\title{
Brassinosteroids Reciprocates Heavy Metals Induced Oxidative Stress in Radish by Regulating the Expression of Key Antioxidant Enzyme Genes
}

\author{
Indu Sharma ${ }^{1 *}$, Ashutosh Sharma ${ }^{1}$, Pratap Pati ${ }^{2}$, Renu Bhardwaj $^{3}$ \\ ${ }^{1}$ DAV University - Department of Agriculture, Jalandhar, Punjuab, India. ${ }^{2}$ Guru Nanak Dev University - \\ Department of Biotechnology, Amritsar, Punjab, India. ${ }^{3}$ Guru Nanak Dev University - Botanical and Environmental \\ Sciences, Amritsar, Punjab, India
}

\begin{abstract}
Heavy metal toxicity in plants lead to accumulation of reactive oxygen species (ROS). Antioxidant enzyme system is also not able to revert altered ROS homeostasis. The present study reports the heavy metal induced ROS toxicity by up-regulating the expression of key antioxidant enzyme genes through Brassinosteroids pre-soaking treatment in radish.
\end{abstract}

Keywords: Brassinosteroids, oxidative stress, antioxidant enzymes, gene expression

*Author for correspondence: indu.gndu@yahoo.com 


\section{INTRODUCTION}

Anthropogenic activities have posed a serious threat of heavy metal pollution. These heavy metals further get incorporated in the food chain and thereby degrade the ecosystem ${ }^{1}$. Through metal contaminated soils, the heavy metals get infiltrated into the plants. Although plants have developed various mechanisms to overcome heavy metal induced phyto-toxicity, yet their accumulation beyond the threshold concentrations lead to severe oxidative stress $^{1,2}$. In plants, heavy metals affect the normal growth, development, reproduction, photosynthesis and accumulation of osmolytes, proteins, carbohydrates as well as polynucleotides ${ }^{3,4}$. Our previous studies reported that cadmium $(\mathrm{Cd})$ and chromium $(\mathrm{Cr})$ stress leads to suppression of normal plant metabolism in radish $^{3,5}$. However, application of Brassinosteroids (BRs), the polyhydroxylated steroidal plant hormones, helps in overcoming the metal induced oxidative stress in plants $^{5,6}$. However, BRs-mediated stresses tolerances are highly depend on their specific concentration and mode of application ${ }^{3,4,5}$. The optimum concentration of BRs that can enhance plant adaptability varies with plant species, developmental stage and environmental conditions ${ }^{7}$. We have earlier reported that seed pre-soaking treatments of two commercially available (and biochemically active) BRs viz., 24-epibrassinolide (EBL) and 28-homobrassinolide (HBL) are most effective at $10^{-7} \mathrm{M}$ concentration ${ }^{3,4,5}$. Furthermore, BRs mediate the process of stress amelioration by interacting with other hormones, regulating the activities of several antioxidant enzymes and expression of various genes though different metabolic pathways ${ }^{6,7}$. Therefore, the present study was carried out to study the effect of $10^{-7} \mathrm{M}$ EBL or HBL on the regulation of gene expression of key antioxidant enzymes in radish seedlings under $\mathrm{Cd}$ or $\mathrm{Cr}$ metal toxicity. The certified and disease-free seeds of radish (Raphanus sativus L. var. Pusa Chetki) were surface sterilized with $0.4 \%$ sodium hypochlorite for $15 \mathrm{~min}$ followed by repeated washings by sterile distilled water. Further, the seeds were given 8-hour presoaking treatment with different concentrations $\left(0\right.$ and $\left.10^{-7} \mathrm{M}\right)$ of EBL (24-epibrassinolide) or HBL (28-homobrassinolide). These pre-treated seeds were then germinated on Whatman No. 1 filter paper lined pre-sterilized glass petridishes $(10 \mathrm{~cm}$ diameter, 20 seeds/dish) each containing different concentrations $(0$ and $0.5 \mathrm{mM})$ of $\mathrm{Cd}$ salt [i.e., $\mathrm{Cd}$ (II) from Cadmium chloride anhydrous $\left.\left(\mathrm{CdCl}_{2}\right)\right]$ or different concentrations $(0$ and 1.0 $\mathrm{mM}) \mathrm{Cr}$ salt [i.e., $\mathrm{Cr}$ (VI) from Potassium chromate $\left(\mathrm{K}_{2} \mathrm{CrO}_{4}\right)$ ]. The IC-50 value (i.e., value of that concentration of heavy metal at which $50 \%$ growth of the radish seedlings is inhibited) of both heavy metal was used to conduct the present study. Therefore, to calculate IC-50 value a range of various concentrations from $0 \mathrm{mM}$ to $5.0 \mathrm{mM}$ of either $\mathrm{Cd}$ or $\mathrm{Cr}$ was prepared. The IC-50 value for $\mathrm{Cd}$ (II) and $\mathrm{Cr}$ (VI) was obtained as $0.5 \mathrm{mM}$ $\mathrm{Cd}$ and $1.0 \mathrm{mM} \mathrm{Cr}$ respectivelty. The experiment was conducted under controlled conditions of light ( $16 \mathrm{~h}$ photoperiod under fluorescent white light with $175 \mu \mathrm{mol} \mathrm{m} \mathrm{m}^{-2} \mathrm{~s}^{-}$ ${ }^{1}$ intensity), temperature $\left(25 \pm 5^{\circ} \mathrm{C}\right)$ and relative humidity $(80-90 \%)$.

The shoots of 7-days old radish seedlings treated with $10^{-7} \mathrm{M}$ EBL alone, $10^{-7} \mathrm{M} \mathrm{HBL}$ alone, control, $0.5 \mathrm{mM} \mathrm{Cd}$ alone, $1.0 \mathrm{mM} \mathrm{Cr}$ alone and $0.5 \mathrm{mM} \mathrm{Cd}$ or $1.0 \mathrm{mM} \mathrm{Cr}$ in combination with HBL and EBL were harvested and immediately kept in liquid nitrogen. They were stored at $-80^{\circ} \mathrm{C}$ until subsequent isolation of RNA was done.

Total RNA was isolated through TRIzol method for RNA isolation. In plant tissue $\left(100 \mathrm{mg}\right.$ ) homogenized in liquid nitrogen, $1 \mathrm{~mL}$ TRIzol (RNAzol ${ }^{\circledR} \mathrm{RT}$ ) was added followed by vortex for $60 \mathrm{~s}$. Then, reaction mixture was incubated for $10 \mathrm{~min}$ with slow-agitation followed by centrifugation at $12,000 \mathrm{~g}$ for $10 \mathrm{~min}$ at $4^{\circ} \mathrm{C}$. Later, $200 \mu \mathrm{L}$ chloroform was added to the supernatant and mixed vigorously by vortexing it for 15 s. After incubating for $7 \mathrm{~min}$ at room temperature, the reaction mixture was centrifuged at $12,000 \mathrm{~g}$ for $15 \mathrm{~min}$ at $4^{\circ} \mathrm{C}$ and transferred the clear aqueous phase into a new tube. To this, $650 \mu \mathrm{L}$ of solution [that contained iso-propanol and sodium citrate $(0.8 \mathrm{M})$ /sodium chloride $(1.2 \mathrm{M})$ mixed in equal ratio] was added and mixed gently. 
After incubating at $4^{\circ} \mathrm{C}$ for $15 \mathrm{~min}$, reaction mixture was centrifuged at $12,000 \mathrm{~g}$ for $10 \mathrm{~min}$ at $4^{\circ} \mathrm{C}$. The pellet was subsequently washed with $1 \mathrm{~mL}$ of $70 \%$ ethanol followed by centrifugation at $12,000 \mathrm{~g}$ for $2 \mathrm{~min}$ at $4^{\circ} \mathrm{C}$. Then, the pellet was air-dried in laminar flow for $10 \mathrm{~min}$ and further dissolved in $20 \mu \mathrm{L}$ pre-chilled RNase freewater.

Isolated RNA was quantified spectrophotometricaly (Perkin Elmer Lambda 25, UVVisible spectrophotometer), and $4 \mu \mathrm{g}$ RNA was used to prepare cDNA. AuPrep Gold cDNA Synthesis Kit (Life Technologies, India) was used to prepare cDNA following the methodology and reagents provided by Kit manufacturers. The cDNA synthesized from seedling mRNA was used as template for PCR or amplification with specific primers. Degenerate oligonucleotide primers (Table 1) corresponding to conserved regions in the plant $S O D^{8}$ and $C A T$ genes ${ }^{9}$ were used as primers for PCR reactions. Tubulin (Tub2) was used as a housekeeping control. The program included denaturation at $94^{\circ} \mathrm{C}$ for $5 \mathrm{~min}$; followed by 40 PCR cycles of annealing at $45^{\circ} \mathrm{C}$ for $1 \mathrm{~min}$, and polymerization at $72^{\circ} \mathrm{C}$ for $2 \mathrm{~min}$. The results of amplified PCR product were analyzed on ethidium bromide stained $1 \%$ agarose gel under ultra-violet light using Gel documentation system (BIORAD-GEL DOC, Milan, Italy). Analysis of relative band intensity (i.e. integrated density values or IDVs) was performed using AlphaEase ${ }^{\circledR} \mathrm{FC}$ software, Version 6.0.0, Alpha Innotech Corporation.

Table 1. List of Primers Used

\begin{tabular}{ll}
\hline Primer & Nucleotide sequence of the Primers \\
\hline 1) CAT1 & F: CTGAACGTGAGACCAAGCATC \\
2) CAT1 & R: TAACAGCATGAGACAAAACCA \\
3) CAT2 & F: CGTCTCAATGTAAGGCCAAGCA \\
4) CAT2 & R: TCAAATAAAATAATAGTCGTCGAA \\
5) CAT3 & F: CTGAACGTGAGGCCAAGCATC \\
6) CAT3 & R: TAGTACTGCGTTTATTTTCATTGA \\
7) Cu/Zn-SOD & F: CCTGG(AC)CT(CT)CATGG(GC)TT(CT)CAT \\
8) Cu/Zn-SOD & R: CTGAG(ATG)TC(AG)TGTCC(AT)CCCTT \\
9) Fe-SOD & F: CT(CT)CC(AT)GC(AT)TTCAACAA(TC)GC \\
10) Fe-SOD & R: GTA(AT)GCATG(TC)TCCCA(AG)AC(AG)TC \\
11) Mn-SOD & F: GA(AG)GG(AT)GGTGG(GTC)GA(GA)CC(GAT)CC \\
12) Mn-SOD & R: GTA(AT)GCATG(TC)TCCCA(AG)AC(AG)TC \\
13) TUB2 & F: 5'-ATCCGTGAAGAGTACCCAGAT-3' \\
14) TUB2 & R: 5'-AAGAACCATGCACTCATCAGC-3' \\
\hline
\end{tabular}

Both EBL and HBL were observed to increase the expression of Cat1, Cat2, Cat3, Cu/ZnSod, FeSod and MnSod (Fig.1, 2) when compared with only heavy metals (Cd or Cr) stressed radish seedlings. However, seed pre-soaking treatments of BRs alone could not change the expression of these antioxidant enzymes in comparison to untreated radish seedlings. Besides, applications of BRs or metal treatments had no significant effect on constitutively expressed Tub2 genes in treated or untreated radish seedlings. The detailed analysis of influence of BRs (EBL or HBL) on regulation of expression of antioxidant genes with respect to untreated seedlings in heavy metals $(\mathrm{Cr}$ or $\mathrm{Cd}$ ) stressed radish seedlings were described in terms of fold change in band intensity in terms of relative IDVs. 

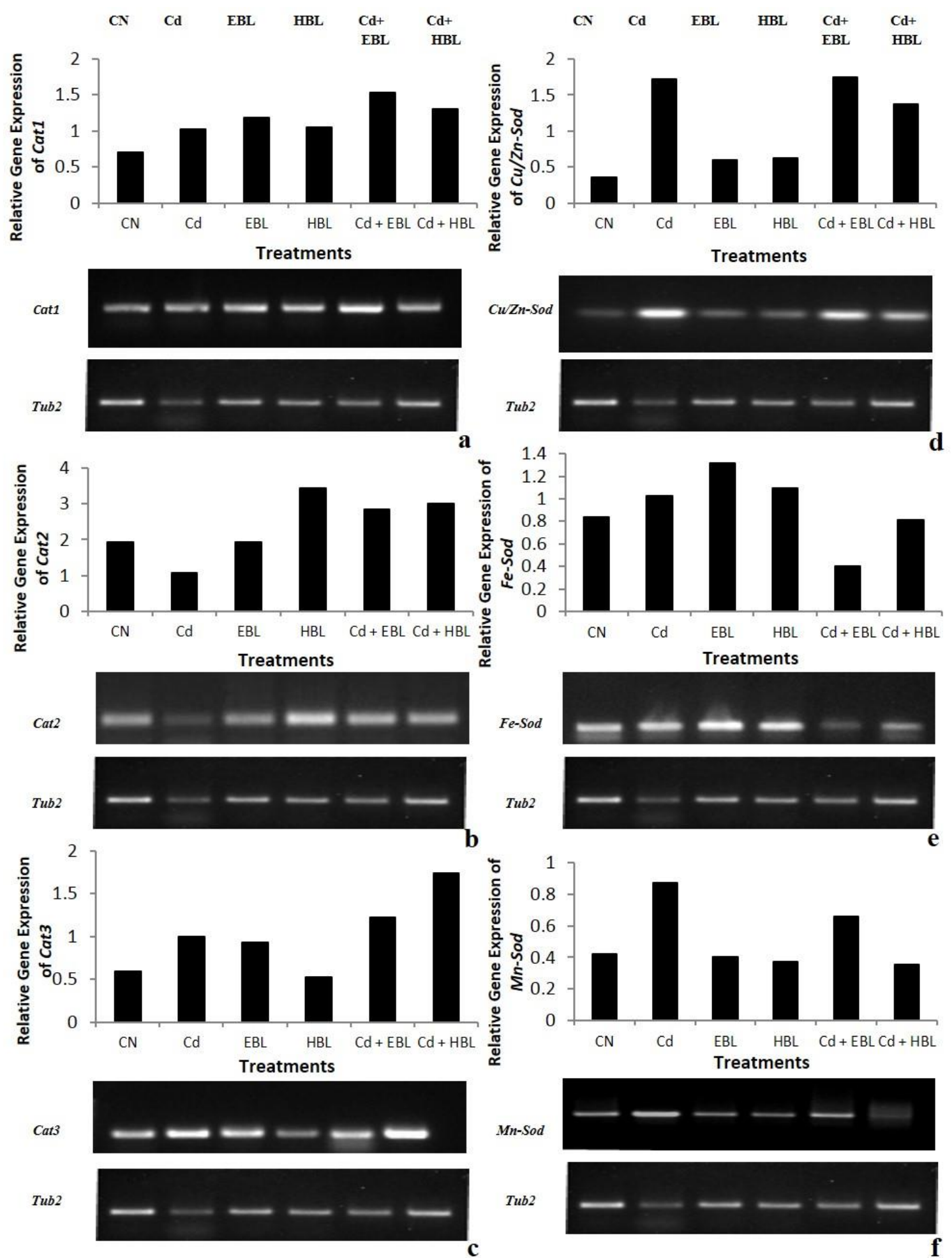

Figure 1. An ethidium bromide stained agarose gel electrophoresis products from reverse transcriptase PCR of 7 days old radish seedlings exposed to distilled water (Control, CN), $0.5 \mathrm{mM} \mathrm{Cd}, 10^{-7} \mathrm{M} \mathrm{EBL}$ (EBL), $10^{-7} \mathrm{HBL}$ (HBL), both 0.5 $\mathrm{mM} \mathrm{Cd}$ and $10^{-7} \mathrm{M} \mathrm{EBL}(\mathrm{Cd}+\mathrm{EBL})$, both $0.5 \mathrm{mM} \mathrm{Cd}$ and $10^{-7} \mathrm{M} \mathrm{HBL}(\mathrm{Cd}+\mathrm{HBL}$ ) for various key antioxidant genes: (a) Cat1, (b) Cat2, (c) Cat3, (d) Cu/Zn-Sod, (e) $\mathrm{Fe}$-Sod and (f) $\mathrm{Mn}$-Sod. Results were first normalized to the housekeeping gene $T u b 2$, and then the relative expression of genes under various treatments was determined. 

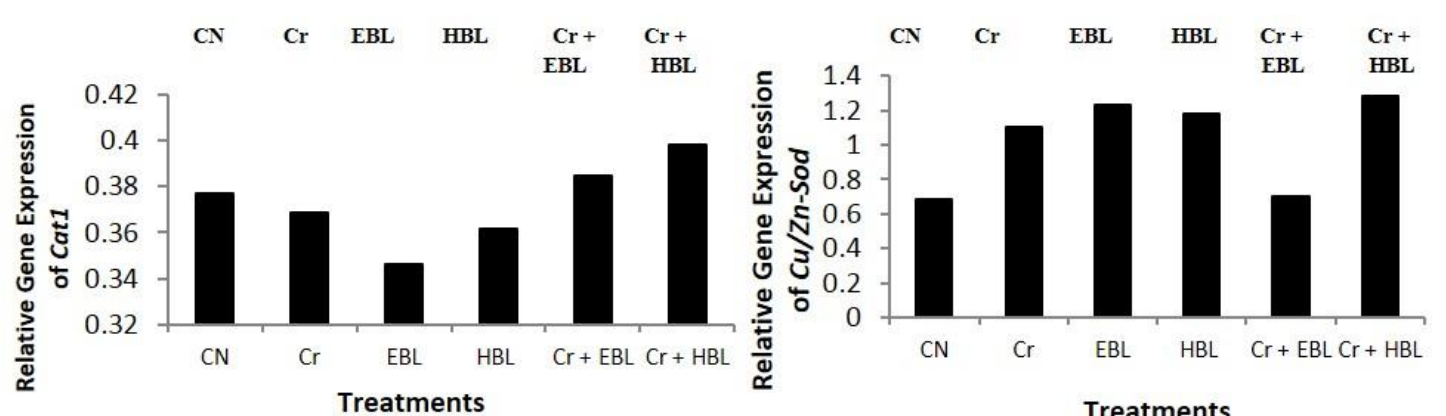

Cat
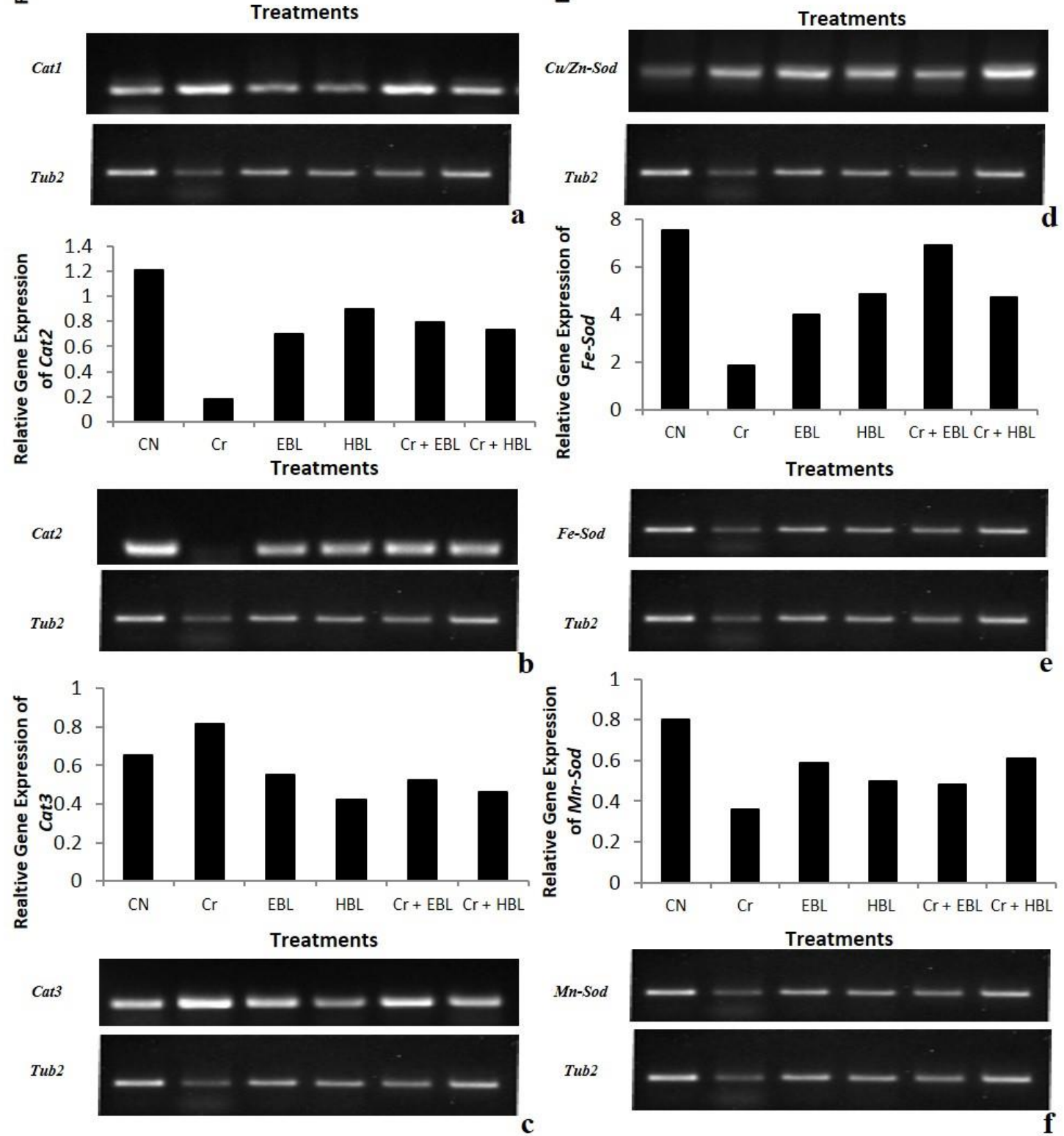

Mn-Sod

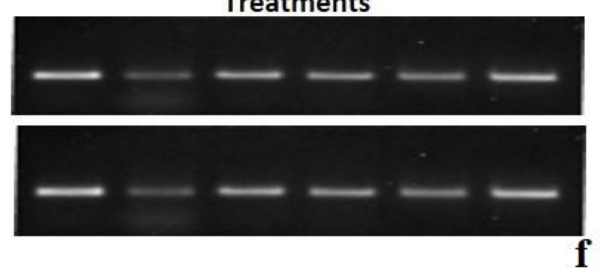

Figure 2. An ethidium bromide stained agarose gel electrophoresis products from reverse transcriptase PCR of 7 days old radish seedlings exposed to distilled water (Control, CN), $1.0 \mathrm{mM} \mathrm{Cr}(\mathrm{Cd}), 10^{-7} \mathrm{M} \mathrm{EBL}(\mathrm{EBL}), 10^{-7} \mathrm{HBL}(\mathrm{HBL})$, both $1.0 \mathrm{mM} \mathrm{Cr}$ and $10^{-7} \mathrm{M}$ EBL (Cr+EBL), both $1.0 \mathrm{mM} \mathrm{Cr}$ and $10^{-7} \mathrm{M} \mathrm{HBL}(\mathrm{Cr}+\mathrm{HBL})$ for various key antioxidant genes: (a) Cat1, (b) Cat2, (c) Cat3, (d) Cu/Zn-Sod, (e) Fe-Sod and (f) $\mathrm{Mn}$-Sod. Results were first normalized to the housekeeping gene $T u b 2$, and then the relative expression of genes under various treatments was determined.

Cd metal treatments at $0.5 \mathrm{mM}$ concentration revealed significant up-regulation of all genes of SOD and CAT except the expression of Cat2 (Fig. 1a) and FeSod (Fig.1e). Furthermore, no such remarkable change in the expression of Tub2 gene was observed 
under Cd or BRs treatments (Fig. 1). The folds change in gene expression of Catl (1.129 times), Cat3 (1.291 times) and MnSod (1.599 times) was high, while maximum change was recorded in gene expression of $\mathrm{Cu} / \mathrm{ZnSod}$ (3.646 times) during Cd Stress in comparison to untreated seedlings (Fig. 1a, c, d and f). When compared with housekeeping gene, the maximum up-regulation in the expression of $\mathrm{Cu} / \mathrm{ZnSod}$ gene was recorded under Cd stress (Fig.1d). Also, seed-presoaking treatments were observed to up-regulate the gene expressions of Cat1, Cat 2 and Cat 3 in Cd stressed radish shoots (Fig. 1a, b and c).

Cd-phytotoxicity up-regulated the gene expressions of $\mathrm{Cu} / \mathrm{ZnSod}$ (Fig. 1d) and $\mathrm{MnSod}$ (Fig. 1f) which was further stimulated by seed pre-sowing applications of EBL and HBL at $10^{-7} \mathrm{M}$. However, no such enhancing impact of BRs pre-treatment was observed in the expression of $\mathrm{FeSod}$ in radish seedlings subjected to Cd toxicity (Fig. 1e). The maximum fold change (3.256 times) in expression of $\mathrm{Cu} / \mathrm{ZnSod}$ was induced by EBL when compared to untreated seedlings. Also, a similar up-regulating effect of HBL on gene expression of $\mathrm{Cu} / \mathrm{ZnSod}$ was observed. The applications of HBL and EBL showed 1.741 and 1.369 folds change in expression of $\mathrm{Cu} / \mathrm{ZnSod}$ gene in $\mathrm{Cd}$ stressed radish seedlings. Also, 0.404 and 0.662 times respective change in gene expressions of $\mathrm{FeSod}$ and $\mathrm{MnSod}$ was observed in EBL treated radish shoots during Cd toxicity. Also, HBL pre-sowing application resulted in 0.808 and 0.353 folds change in gene expressions of FeSod and MnSod in Cd stressed radish seedlings (Fig. 1e and f).

The Cd metal down-regulated the expression of Cat 2 gene which was further enhanced significantly by treatments of EBL and HBL in comparison to only metal treated radish seedlings (Fig. 1b). Though both EBL and HBL up-regulated the gene expression of CAT but HBL induced highest up-regulation (1.794 times) in expression of Cat 3 when compared with untreated seedlings (Fig. 1c). With respect to Tub2 gene, expression of Cat 2 was up-regulated to 2.85 folds and 3 folds under influence of EBL and HBL respectively. Also, 1.535 and 1.214 times change in expression of Cat1 and Cat 3 was recorded in EBL-treated seedlings subjected to Cd stress. Similarly, 1.309 and 1.741 folds change in gene expression of Cat1 and Cat3 was noticed under the influence of HBL treated seedlings exposed to Cd toxicity. Thus, expression of Cat 2 gene was observed to be maximum up-regulated under $\mathrm{Cd}$ stressed seedlings pre-treated with HBL and EBL (Fig. 1b).

In radish seedlings, $\mathrm{Cr}$ metal at $1.0 \mathrm{mM}$ concentration resulted in up-regulation of Cat 1 , $\mathrm{Cat} 3$ and $\mathrm{Cu} / \mathrm{ZnSod}$ genes, however gene expressions of Cat2, FeSod and MnSod were observed to be down-regulated remarkably (Fig. 2). About 0.166, 0.267, 0.490 folds change in expression of Cat2, FeSod and MnSod was observed in Cr-stressed radish seedlings with respect to untreated seedlings (Fig. 2b, e and f). Whereas 1.072, 1.365 and 1.761 times change in expressions of Cat $1, \mathrm{Cat} 3$ and $\mathrm{Cu} / \mathrm{ZnSod}$ were observed (Fig. 2a, c and d). In comparison to Tub2 gene, the expression of FeSod was reported to show maximum (1.8 folds) change under Cr stress (Fig. 2e). However, 1.6 times fold change in expression of $\mathrm{Cu} / \mathrm{ZnSod}$ was recorded during $\mathrm{Cr}$ toxicity in comparison to control. Though expression of $C A T$ genes and $S O D$ genes were regulated under Cr stress yet, maximum folds change in the expressions of $\mathrm{Cu} / \mathrm{ZnSod}$ and $\mathrm{FeSod}$ were observed in comparison to Tub2 gene (Fig.2).

The down-regulated expressions of FeSod (Fig. 2e) and MnSod (Fig. 2f) were remarkably reversed by pre-sowing applications of EBL and $\mathrm{HBL}$ at $10^{-7} \mathrm{M}$ to $1.0 \mathrm{mM}$ $\mathrm{Cr}$ stressed radish seedlings. Applications of EBL and HBL showed 4.867 and 6.875 times change in expression of $\mathrm{FeSod}$ under $\mathrm{Cr}$ when compared with only $\mathrm{Cr}$ treated (1.836 folds) radish shoots. In addition to this, a stimulating effect of HBL was observed on the expression of $\mathrm{Cu} / \mathrm{ZnSod}$ gene in shoots of radish seedlings under Cr toxicity (Fig. 2d). In comparison to untreated seedlings the maximum increase with HBL treatment was recorded in the gene expression of $\mathrm{Cu} / \mathrm{ZnSod}$ in $\mathrm{Cr}$ stressed radish shoots. 
Seed pre-soaking treatments significantly up-regulated the gene expression of Cat 1 and Cat 2 except the expression of Cat 3 in shoots of radish exposed to Cr toxicity (Fig. 2 ac). However, HBL induced maximum change (1.412 folds) in the gene expression of Catl when compared to $\mathrm{Cr}$ (1.072 times) in comparison to untreated seedlings (Fig. 2a). In case of Cat2, maximum increase was recorded under HBL (0.790 folds) and EBL (0.731 folds) treatments when compared with only Cr stressed (0.182) seedlings (Fig. $2 b)$.

During various abiotic stresses, cellular homeostasis is altered and ROS production is elevated. Heavy metals like chromium induce oxidative stress in plant that is mediated by NADPH oxidase ${ }^{10,11}$. An up-regulation in heavy metal-specific, superoxide $\left(\mathrm{O}_{2}{ }^{-}\right)$ generating NADPH oxidase genes have also been recorded ${ }^{12}$. Among various antioxidant enzymes involved in antioxidant defence system, SOD and CAT enzymes are most significant for the removal of superoxide radicals and its conversion into $\mathrm{H}_{2} \mathrm{O}$ and $\mathrm{O}_{2}{ }^{1,5}$. We have previously reported that seed-presoaking treatments of BRs significantly improved the specific activities of SOD and CAT enzymes under $\mathrm{Ni}, \mathrm{Cd}$ and $\mathrm{Cr}$ stress in radish ${ }^{3,4,5}$. Both EBL and HBL were found to be most effective at the dose of $10^{-7} \mathrm{M}$ in ameliorating the heavy metals induced oxidative stress by modulating the activities of antioxidant enzymes, antioxidants and various others important biochemical components. Therefore, the molecular studies on the key antioxidant enzymes are pre-requisite to understand further underlying mechanism of action of BRs in stress alleviation. Hence, the present study is an insight into the molecular mechanism of differential gene expression of $S O D$ and $C A T$ genes under influence of BRs during metals induced oxidative stress in radish.

In the present study, seed pre-soaking treatments of HBL up-regulated the expression of $\mathrm{Cu} / \mathrm{ZnSod}, \mathrm{MnSod}$, Cat1, Cat2 and Cat 3 whereas EBL also stimulated FeSod expression in radish seedlings under Cd stress (Fig. 1). Further in Cr stressed seedlings, gene expression of SOD and CAT was up-regulated except Cat2 gene (Fig. 2) Since $\mathrm{Cu} / \mathrm{ZnSod}$ is most common SOD and acts in cytosol, chloroplast and peroxisomes therefore, metal induced generation of ROS may have enhanced its expression under stress ${ }^{1,5}$. Further, to negate the effect of ROS on plasma-membranes or plants cells, BRs may have directly enhanced the expression of $\mathrm{Cu} / \mathrm{ZnSod}$. Also, FeSod dismutates the superoxide radical to $\mathrm{H}_{2} \mathrm{O}_{2}$ in chloroplasts ${ }^{5}$. It is feasible that role of $\mathrm{FeSod}$ was also partly carried out by $\mathrm{Cu} / \mathrm{ZnSod}$ thus resulting in stimulation of its gene expression. However, Cat 1, Cat 2 and Cat 3 genes are localized in peroxisomes where they convert $\mathrm{H}_{2} \mathrm{O}_{2}$ into $\mathrm{H}_{2} \mathrm{O}$ thereby reducing oxidative damage in plant cells ${ }^{1,5}$. All CAT genes at same time or in co-ordination contribute for detoxification of $\mathrm{H}_{2} \mathrm{O}_{2}$ in peroxisomes.

A recent study ${ }^{13}$ indicated that exogenous EBL increased the expression of the dehydroascorbate reductase (Dhar), glutathione reductase (Gr), monodehydroascorbate reductase (Mdhar), and glutathione synthetase (Gs) in the leaves of zinc stressed Solanum melongena $\mathrm{L}$. Wu and co-workers ${ }^{13}$ also suggested that EBL can potentially regulate the regeneration of related antioxidants at the transcriptional level. Similarly, the exogenous EBL treatment up-regulated the expression of Sod, Cat, ascorbate peroxidase (Apx) and $G r$ under Cr stress in rice ${ }^{14}$. Therefore, it is possible that the stress responses in BRs treated or untreated shoots of radish might be regulated by antioxidant enzymes and some other signals ${ }^{15}$. Although the signaling pathway of action of BRs have been studied by using diverse genomic and proteomic approaches, but still there are various unknown components are unsolved ${ }^{16}$. Therefore, detailed understanding of mechanism of BRs mediated stress-mitigation is pre-requisite. Such thorough studies might reveal the complex sequence of metabolic shifts, like enhancement or suppression of key enzymatic reactions, induction of protein synthesis and the production of various defence related bio-chemicals in plants through the application of BRs. 
Brassinosteroids (BRs) when applied at specific dose can ameliorate the heavy metal toxicity in plants which is mediated by regulation of the expressions of key antioxidant genes. Therefore, BRs may be implicated in plant stress-protection and enhancing their productivity under heavy metal stress conditions. Further studies on underlying mechanisms of interactions of BRs with other plant growth regulators might provide more efficient phytohormone-based agronomic practices to reduce the risk of crops being exposed to metal contaminated soils.

\section{ACKNOWLEDGMENTS}

This investigation was financially assisted by Department of Science and Technology (DST) and DST-INSPIRE Fellowship Program, Ministry of Science \& Technology, Government of India, New Delhi, India.

\section{REFERENCES}

1. Rajewska I, Talarek M, Bajguz. Brassinosteroids and Response of Plants to Heavy Metals Action. Front Plant Sci. 2016; 7: 629.

2. Vardhini BV. Brassinosteroids are potential ameliorators of heavy metal stresses in plants. In: Ahmad P, editor. Plant Metal Interaction. Amsterdam: Elsevier; 2016. P. 209-237.

3. Sharma I, Pati PK, Bhardwaj R. Regulation of growth and antioxidant enzyme activities by 28-homobrassinolide in seedlings of Raphanus sativus L. under cadmium stress. Indian J Biochem Biophys. 2010; 47(3): 172-177.

4. Sharma I, Pati PK, Bhardwaj R. Effect of 24-epibrassinolide on oxidative stress markers induced by nickel-ion in Raphanus sativus L. Acta Physiol Plant. 2011; 33(5): 1733-1735.

5. Sharma I, Pati PK, Bhardwaj R. Effect of 28-homobrassinolide on antioxidant defence system in Raphanus sativus L. under chromium toxicity. Ecotoxicology. 2011; 20(4):862874

6. Fariduddin Q, Yusuf M, Ahmad I, Ahmad A. Brassinosteroids and their role in response of plants to abiotic stresses. Biol Plant. 2014; 58(1): 9-17.

7. Ahammed GJ, Xia XJ, Li X, Shi K, Yu JQ, Zhou YH. Role of brassinosteroid in plant adaptation to abiotic stresses and its interplay with other hormones. Curr Protein Pept Sci. 2015; 16(5):462-473.

8. Kwon SI, An CS. Differential expression of two SOD (superoxide dismutase) genes from small radish (Raphanus sativus L. var. sativus). J Plant Biol. 2006; 49(6): 477-483.

9. Kwon SI, Lee H, An CS. Differential expression of three catalase genes in the small radish (Raphanus sativus L. var. sativus). Mol Cells. 2007; 24(1): 37-44.

10. Jakubowska D, Janicka-Russak M, Kabała K, Migocka M and Reda M. Modification of plasma membrane NADPH oxidase activity in cucumber seedling roots in response to cadmium stress. Plant Sci. 2015; 234: 50-59.

11. Kaur G, Sharma A, Guruprasad K, Pati PK. Versatile roles of plant NADPH oxidases and emerging concepts. Biotechnol Adv. 2014; 32(3): 551-563.

12. Remans T, Opdenakker K, Smeets K, Mathijsen D, Vangronsveld J, Cuypers A. Metalspecific and NADPH oxidase dependent changes in lipoxygenase and NADPH oxidase gene expression in Arabidopsis thaliana exposed to cadmium or excess copper. Funct Plant Biol. 2010; 37(6): 532-544.

13. Wu XX, Chen JL, Xu S, Zhu ZW, Zha DS. Exogenous 24-epibrassinolide alleviates zincinduced toxicity in eggplant (Solanum melongena L.) seedlings by regulating the glutathione-ascorbate-dependent detoxification pathway. J Hortic Sci Biotechnol. 2016; 91(4): 412-420.

14. Sharma P, Kumar A, Bhardwaj R. Plant steroidal hormone epibrassinolide regulate-Heavy metal stress tolerance in Oryza sativa L. by modulating antioxidant defense expression. Environ Exp Bot. 2016; 122: 1-9.

15. Xia X-J, Zhou Y-H, Ding J, Shi K, Asami T, Chen Z, Yu J-Q. Induction of systemic stress tolerance by brassinosteroid in Cucumis sativus. New Phytol. 2011; 191(3):706-720 
16. Tang W, Deng Z, Wang ZY. Proteomics shed light on the brassinosteroid signaling mechanisms. Curr Opin Plant Biol. 2010; 13: 27-33.

Received: July 30, 2016 Accepted: October 07, 2016 